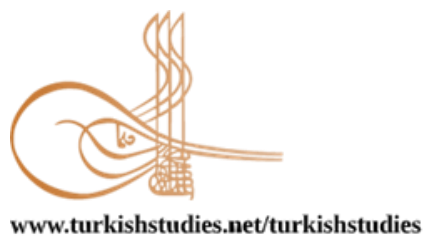

Turkish Studies

www.turkishstudies.net/turkishstudies

eISSN: $1308-2140$

BALKAN
UNIVERSITY

Sponsored by IBU

Research Article / Araștırma Makalesi

\title{
COVID-19 Pandemi Sürecinde Sağlık Birimlerinin Yapımı için Yeni Bir Proje Teslim Sistemi Olarak Yapım Yönetimi Modeli
}

\author{
Construction Management System as a New Project Delivery System for the Construction of Health \\ Units During the COVID-19 Pandemic Process
}

\author{
İkbal Erbaș*
}

\begin{abstract}
COVID-19 disease emerged as a regional problem in China in December 2019, but it spread to the whole world in a short time and became a global problem. This epidemic, which also includes our country, has not only been a health problem but also made it necessary to develop strategic solutions in economic and sociological terms. Therefore, decisions, incentive packages, and management strategies took in parallel with the pace of the epidemic are important in terms of completing the process with the least loss. The success of the health system in this process depends on the quality of the health personnel, but it is directly proportional to the quality and capacity of the health units. Considering the possibility of existing health units not meeting the required demand in terms of both bed capacity and health equipment, the issue of how to provide new temporary and permanent health units that will serve as a pandemic hospital also gains importance and urgency. In the process of combating the COVID-19 pandemic, it is important to complete the construction activities of the health structures that are subject to the Public Procurement Law. Otherwise, emerging health demand will not be met. This will cause the health system to collapse, as seen in most European countries. Any construction activity to be carried out by the public is subject to the Public Procurement Law (PPL). However, the Public Procurement Law has a problematic structure that affects project cost, quality, and duration. The aim of this study is to reveal the main advantages of adapting the Construction Management Project Delivery System to the PPL for delivery of health units that will be built during the COVID-19 pandemic process. For this purpose within the scope of the study, the advantages of the construction management system to the public administrations will be evaluated in terms of its effect on the duration, cost, and quality of the work. In the long term, it is expected that the study will serve as a guide for the necessary legislative changes to be implemented in PPL.
\end{abstract}

Structured Abstract: COVID-19 disease, which first appeared in Wuhan, China in December 2019, affected the whole world in a short time due to the rapid spread of it. On January 30, 2020, the World Health Organization (WHO) announced that the COVID-19 outbreak was an Internationally Important Public Health Emergency. As of March, COVID-19 cases have been reported in 77 countries (WHO, 2020). This epidemic, which also includes our country, has not only been a health problem but also made it necessary to develop strategic solutions in economic, and sociological terms. Decisions, incentive packages and management strategies taken in parallel with the pace of the epidemic are important in terms of completing the process with the least loss.

\footnotetext{
* Doç. Dr., Akdeniz Üniversitesi, Mimarlık Fakültesi, Mimarlık Bölümü

Assoc. Prof. Dr. Akdeniz University, Facuty of Architecture, Department of Architecture

ORCID 0000-0002-6327-1399

ierbas@akdeniz.edu.tr

Cite as/ Atıf: Erbaş, İ. (2020). COVID-19 pandemi sürecinde sağlık birimlerinin yapımı için yeni bir proje teslim sistemi olarak yapım yönetimi modeli. Turkish Studies, 15(6), 433-445. https://dx.doi.org/10.7827/TurkishStudies.44100

Received/Geliș: 08 June/Haziran 2020

Accepted/Kabul: 15 October/Ekim 2020

Checked by plagiarism software

Copyright $(\mathrm{C}$ MDE, Turkey

Published/Yayın: 20 October/Ekim 2020

CC BY-NC 4.0
} 
In the process of COVID-19 pandemic, how the health units will be constructed poses an important problem. In Turkey, the construction of health units is subject to the Public Procurement Law No. 4734 (PPL). The PPL requires the implementation of a traditional project delivery system. The purpose of this study is to reveal the benefits of adopting the Construction Management Project Delivery System to the PPL in the provision of health units to be built in the COVID-19 pandemic process. For this purpose, the weaknesses of the PPL within the scope of the study affecting the duration, cost and quality in the construction works were identified, and the work flow process and participant relations of the traditional project delivery system and the construction management project delivery system that had to be implemented in accordance with the PPL were compared.

In the traditional project delivery system, the owner first contracts with the designer for design service. After all the design documents (architectural project, static project, etc.) are completed, the owner chooses the general contractor. The main criterion in the selection of the general contractor is the selection of the "economically most advantageous bidder". For this reason, the bidder submitting the lowest bid is selected. In this process, no contractual relationship is established between the designer and the general contractor. The most important disadvantage of this system is that the contractor is not involved in the design phase.

When the traditional system is evaluated in terms of duration, it is seen that the completion of the public construction works take a long time since the construction phase cannot be started before the design is completed.

In the traditional system, all the projects should be finished before the tender process. In this way, the owner is informed about the cost of the project at the beginning of the construction. But when a change order occurs the cost of the contract changes as well. Therefore when the system is evaluated in terms of the cost, reflecting the changes to the construction contract is difficult in this system.

When the evaluation is made in terms of the quality, it is seen that the contractor, who is trying to bid the lowest price in the tender stage to receive the tender, compromises the quality of the work during the construction phase. This situation causes the construction quality of public buildings to decrease.

In the construction management project delivery system the owner contracts with the designer to design phase of the project. In this relationship, the designer is also responsible for preparing contract documents. On the other hand, the contractor undertakes the construction work in accordance with the contract documents. The role of the construction manager in this system is to be the representative and consultant of the owner during both design and construction phases. With his knowledge and experience about construction, he involves the design phase and contributes to the development of the design's shortcomings as a consultant of the owner at this stage. Similarly, he acts as the representative of the owner on site during the construction phase. Unlike the traditional project delivery system, the possible problems are eliminated in the design phase because of the involvement of the construction manager. On the other hand, the construction manager allows cost control during the construction process with cost calculations in both phases. In this system, there is no contractual relationship between the construction manager and other actors. The system also allows the construction and design stages to be carried out simultaneously, unlike the traditional project delivery system.

The main advantages of the construction management project delivery system could be summarized as;

- Establishing good relations between the participants

- Allowing phased construction

- Ensuring separate contracts for different specialties

- Allowing changes without changing the contract

- The construction manager can be included in the design phase

- Allowing cost control

In the process of combating the COVID-19 pandemic, it is important to complete the construction activities of the health units that are subject to the PPL. Otherwise, emerging health demand will not be met. This will cause the health system to collapse, as seen in most European countries. However, the PPL has a problematic structure that affects project cost, quality, and duration. At this point, this study undertakes the 
task of revealing the main advantages that the construction management project delivery system will provide to public administrations as a new project delivery system.

Effective and efficient use of public resources has an important effect on ensuring social welfare and trust. For this reason, the sensitivity required to be carried out in the construction of health units during the COVID-19 pandemic process once again gains importance. In order to meet the increasing demand for healthcare services against COVID-19, it is necessary to build new public health buildings quickly.

Compared with the traditional project delivery system that PPL requires in the implementation of public buildings, the construction management system has been found to provide significant advantages to public administrations in terms of minimum time, maximum quality and minimum cost. It is recommended to consider the adaptation of the construction management system to the PPL in future studies.

Keywords: Architecture, COVID-19, Public Procurement Law, Health Units, Construction Management

Öz: COVID-19 hastalığı 2019 yılı Aralık ayında Çin`de yaşanan bölgesel bir sorun olarak ortaya çıkmış, ancak kısa bir sürede tüm dünyaya yayılarak küresel bir sorun haline gelmiştir. Ülkemizi de içine alan bu salgın, yalnızca bir sağlık problemi olmanın ötesinde aynı zamanda ekonomik ve sosyolojik açılardan stratejik çözümler geliştirmeyi de gerekli kılmıştır. Bu nedenle salgının ilerleme hızına paralel olarak alınan kararlar, teşvik paketleri ve yönetim stratejileri sürecin en az kayıpla tamamlanması açısından önem arz etmektedir. Bu süreçte sağlık sisteminin başarısı sağlık personelinin niteliğine bağlı olmakla birlikte sağlık yapılarının niteliği ve kapasitesiyle de doğru orantılıdır. Mevcut sağlık birimlerinin gerek yatak kapasitesi gerekse sağlık donanımı yönüyle gerekli talebi karşılayamama ihtimali göz önünde bulundurulduğunda, pandemi hastanesi olarak hizmet verecek yeni geçici ve kalıcı sağlık birimlerinin nasıl temin edileceği hususu da önem ve aciliyet kazanmaktadır. COVID-19 pandemisi ile mücadele sürecinde Kamu İhale Kanunu`na (KİK) tabi olan sağlık yapılarının inşa faaliyetlerinin hızlı bir şekilde tamamlanması önemlidir. Aksi takdirde ortaya çıkan sağlık talebi karşılanamayacaktır. Bu durum çoğu Avrupa ülkesinde görüldüğü gibi sağlık sisteminin çökmesine neden olacaktır. Kamu tarafından yapılacak her türlü yapım faaliyeti KİK mevzuatına tabidir. Ancak KİK mevzuatı proje maliyet, kalite ve süresine etki eden iyileştirilmeye ihtiyaç duyulan bir yapıya sahiptir. Bu çalışmanın amacı COVID-19 pandemi sürecinde inşa edilecek sağlık birimlerinin temininde "Yapım Yönetimi Proje Teslim Sisteminin" KİK mevzuatına uyarlanmasının kamu idarelerine sağlayacağı temel avantajları ortaya koymaktır. Bu amaçla çalışma kapsamında "Yapım Yönetimi Proje Teslim Sisteminin" kamu idarelerine sağlayacağı avantajlar yapım işinin süresine, maliyetine ve kalitesine etkisi açısından değerlendirilecektir. Çalışma sonuçlarının Türkiye’de uygulama alanı bulunmayan "Yapım Yönetimi Proje Teslim Sisteminin” kamu ihalelerinde uygulanması için gerekli mevzuat değişikliklerinde bir rehber niteliği taşıması hedeflenmektedir.

Anahtar Kelimeler: Mimarlık, Covid-19, Kamu İhale Kanunu, Sağlık Yapıları, Yapım Yönetimi

\section{Giriş}

İlk olarak 2019 yılı Aralık ayında Çin `in Wuhan kentinde ortaya çıkan COVID-19 hastalığ1 2019 hızla yayılımı nedeniyle kısa sürede tüm Dünya'yı etkisi altına almıştır. 30 Ocak 2020'de Dünya Sağlık Örgütü (DSÖ), COVID-19 salgınının Uluslararası Öneme Sahip Halk Sağlığı Acil Durumu olduğunu duyurmuştur. Mart Ayı itibariyle 77 ülkede COVID-19 vakası bildirilmiştir (WHO, 2020a). Ülkemizi de içine alan bu salgın, yalnızca bir sağlik problemi olmanın ötesinde aynı zamanda ekonomik ve sosyolojik açılardan stratejik çözümler geliştirmeyi de gerekli kılmıştır. Salgının ilerleme hızına paralel olarak alınan kararlar, teşvik paketleri ve yönetim stratejileri sürecin en az kayıpla tamamlanması açısından önem arz etmektedir.

Yeni bir hastalığın tüm dünyayı bir salgınla etkilemesi "pandemi” olarak tanımlanmaktadır. Bir hastalığın pandemi olarak ilan edilebilmesi için istikrarlı bir şekilde, dünyanın farklı noktalarında, kitleler üzerinde görülmeye başlanması gerekir (Çıragil, 2020). COVID-19 hastalığı da taşıdığ 1 bu özellikler sebebiyle DSÖ tarafından pandemi olarak ilan edilmiştir. COVID-19 pandemisi nedeniyle sağlık hizmeti talebi (tanı ve tedavi) her geçen gün artmaktadır. Bu nedenle DSÖ`nün 
yayınladığı rapora göre (2020a) her ülke, hızlı yayılmayı yavaşlatmak ve COVID-19'lu durumu ağır ve ciddi hastalardan dolayı sağlı sistemlerinin çöküş yaşamasını önlemek için acilen gerekli önlemleri almalıdır.

Küresel bir salgının kuşkusuz en büyük etki yarattığı sektörlerin başında sağlık sektörü gelmektedir. Gerek sağlık çalışanlarının çalışma koşulları, hastane ve sağlık kuruluşlarının kapasitesi, sistemin işleyişi, yapılan sağlık harcamaları, küresel salgından önemli oranda etkilenmektedir. Sağlık sektörünün bir ülkede etkili bir biçimde işleyebilmesi için asgari koşulların sağlanabilmesi, vatandaşlarının sağlığının korunması, ihtiyaç duyulduğu kadar sağlık personeli ve hastanenin bulunması gerekmektedir (Yenal, 2020). Mevcut sağlı birimlerinin gerek yatak kapasitesi gerekse sağlık donanımı yönüyle bu talebi karşılayamama ihtimali göz önünde bulundurulduğunda, pandemi hastanesi olarak hizmet verecek yeni geçici ve kalıci sağlık birimlerinin kısa süre içerisinde nasıl temin edileceği hususu da önem ve aciliyet kazanmaktadır. Tibbi olmayan tesisleri yeniden kullanmak ve yoğun talebi karşılamak için geçici veya kalıcı tıbbi tesisler kurulması da DSÖ`nün tavsiyeleri arasındadır (WHO, 2020b).

$\mathrm{Bu}$ süreçte sağlık sisteminin başarısı sağlık personelinin niteliğine bağlı olmakla birlikte sağlık yapılarının da niteliği ve kapasitesiyle de doğru orantılıdır. Hastalığın hızla yayılması talep edilen sağlık hizmetlerinin verilememesine neden olacak ve mevcut sağlik yapılarına ve bu birimlerde görev alan sağlık personeline ağır bir yük getirecektir. Bu nedenle hastaların izole edilmiş alanlarda, özellikle yoğun bakım birimlerinde birebir sağlık hizmeti aldığı bu yapıların sayısının geçici ve kalıcı çözümlerle artırılması oldukça önemlidir. Nitekim İspanya ve İtalya da yaşanan örnekler yetersiz sağlık alt yapısının, gerekli sağlık hizmetinin sunulmasına ne derecede olumsuz etki ettiğinin de bir göstergesi olmuştur. Bu ülkelerde yatak kapasitesi dolan sağlık yapılarında COVID-19 hastaları tedavi edilememiş ve ölüm oranları beklenenin üzerinde gerçekleşmiştir. Statistica verilerine göre 100 bin kişiye düşen yoğun bakım yatak sayısı Türkiye`de 40 iken, İtalya 'da bu say112,5; İspanya'da ise 9,7’dir (Url-1, 2020).

Diğer taraftan İspanya ve İtalya `nın aksine COVID-19 vakalarının ilk görüldüğü şehir olan Çin- Wuhan'da kurulan Huoshenshan sahra hastanesi 10 gün içinde, Leishenshan hastanesi ise yaklaşık 30 gün içinde hizmete açılmıştır. Çin, açılan bu hastaneler sayesinde sağlık sisteminde herhangi bir çöküş yaşamadan COVID-19 vakalarının kontrol altına alınmasını sağlamıştır.

COVID-19'u diğer pandemilerden ayıran en önemli özellik sadece az gelişmiş ülkelerle gelişmekte olan ülkelerde yoğunlaşmamasıdır. Gelişmişlik düzeyinin ötesinde bütün ülkeleri etkisi altına almış olmasıdır (Bingül ve diğ., 2020). COVID-19 kolaylıkla bulaşma riskine sahip bir hastalıktır. Bu nedenle hastaların klinik seyirleri açısından başta yoğun bakım uygulamaları olmak üzere, yatan hastaların tedavilerinde ve ayaktan takip edilen vakaların takip sürecinde her yönüyle donanımlı sağlık birimlerinin acil bir şekilde inşa edilmesi gereklidir. Bu gerekliliğin hastalığın kontrol altına alınması açısından avantaj sağlayacağı Çin örneğinde de görüldüğü üzere oldukça açıktır. Çin`de inşa edilen Huoshenshan ve Leishenshan hastaneleri artan ihtiyacın karşılanmasına imkan tanımıştır. Hastanelerin kısa sürede tamamlanıp hizmete açılmasıyla inşa edildikleri bölgelerde sergi salonlanı, spor merkezleri gibi alanlardan dönüştürülen geçici hastaneler de kapatılmıştır (Url-2, 2020).

COVID-19 pandemisi sürecinde sağlık yapılarının nasıl bir süreçle inşa edilecekleri önemli bir sorun teşkil etmektedir. Kamu yapısı olarak devlet eliyle inşa edilecek bu yapıların gerçekleştirilmesi süreci 4734 sayılı Kamu İhaleleri Kanunu na (KİK) tabidir. KİK yapım sürecinde "tasarım- ihale- yapım" iş sıra düzenine sahip geleneksel proje teslim sistemi (PTS) uygulanmasını zorunlu tutmaktadır. Bu çalışmanın amacı COVID-19 pandemi sürecinde inşa edilecek sağlık birimlerinin temininde, Türkiye`de uygulama alanı bulunmayan Yapım Yönetimi PTS`nin KİK mevzuatına uyarlanmasının kamu idarelerine sağlayacağı yararları ortaya koymaktır. Bu amaçla çalışma kapsamındaki KİK mevzuatının yapım işlerinde süre, maliyet ve kaliteye etki eden zayıf 
yönleri tanımlanacak, her iki sistemin iş akış süreci ve katılımcı ilişkileri arasında karşılaştırma ortamı sağlanacaktır.

\section{Kamu İhale Kanunu`nun Yapım İhalelerindeki Zayıf Yönleri}

Kamu hizmeti faaliyetlerindeki farklılaşmalar ve çeşitlenmeler nedeniyle kamu idarelerinin ihtiyaçları sürekli olarak artmaktadır. Bu ihtiyaçların kamu idarelerinin kendi imkanları ile kaşılanması ise çoğu zaman mümkün olmamaktadır. Bu nedenle kamu idareleri sözkonusu ihtiyaçlarını özel sektörle yaptıkları mal ve hizmet sözleşmeleriyle temin etmektedirler (Kortunay ve Sezer, 2007). Bu amaçla kamu idareleri, kamu hizmeti alımı için farklı sektörle sözleşmeler yapmakta ve bu sözleşmeleri belli bir idari usul olan ihale usulü ile gerçekleştirmektedir. İhale usulü idarelerin tek yanlı işlemler yapmalarını ve bireylerle karşı karşıya gelmelerini engellemektedir. Böylece kamu idarelerinini güvenilir ve şeffaf olma hedefleri de gerçekleşmektedir (Akgül, 2006).

Kamu hukukuna tabi olan, kamunun denetimindeki veya kamu kaynağı kullanan kamu kurum ve kuruluşlarının yapacakları ihalelerde uygulanması zorunlu esas ve usuller, 4734 sayıl1 Kamu İhale Kanunu (KIK) çerçevesinde belirlenmiştir. Bu kanuna göre ihalelerde kullanılacak olan sözleşmelerin hazırlanması ve uygulanmasına ilişkin hususlar 4735 sayılı Kamu İhaleleri Sözleşmeleri Kanunu (KİSK) kapsamında tanımlanmıştır (Akçay ve Manisalı, 2009). Bu kanunların hazırlanmasında birinci derecede başvuru kaynağı Avrupa Birliği normları olmuştur.

4734 sayılı KİK le ihalelerde saydamlığın, rekabetin, eşit muamelenin, güvenilirliğin, gizliliğin, kamuoyu denetiminin, ihtiyaçların uygun şartlarla ve zamanında karşılanmasının ve kaynakların verimli kullanılmasının en kapsamlı şekilde sağlanması, kamu kurum ve kuruluşlarının yapacakları ihalelerde tek bir yasal düzenlemeye tabi olmaları, işlerin istekliler tarafindan piyasa rayiçlerine uygun fiyatlara göre ihale edilmesi hedeflenmiştir (Coşgun, 2009).

KİK madde 21.b. doğal afetler, salgın hastalıklar, can veya mal kaybı tehlikesi gibi ani ve beklenmeyen veya idare tarafından önceden öngörülemeyen olayların ortaya çıkması üzerine ihalenin ivedi olarak yapılmasının zorunlu olması halinde pazarlık usulü ihale yapılabileceğini ön görmektedir. Bu nedenle covid-19 pandemisi sürecinde inşa edilen yapılar pazarlık usulü ile ihale edilmelidir. Ancak inşa edilen 2 pandemi hastanesinin ihale usulüne ilişkin kamuoyuyla henüz herhangibir bilgi paylaşılmamıştır.

KİK yapım işlerinde tasarım, ihale ve yapım sıra düzeninin takip edildiği geleneksel PTS `nin uygulanmasını zorunlu tutmaktadır. Katılımcılar arasındaki ilişki Şekil 1’de tanımlanmaktadır. 


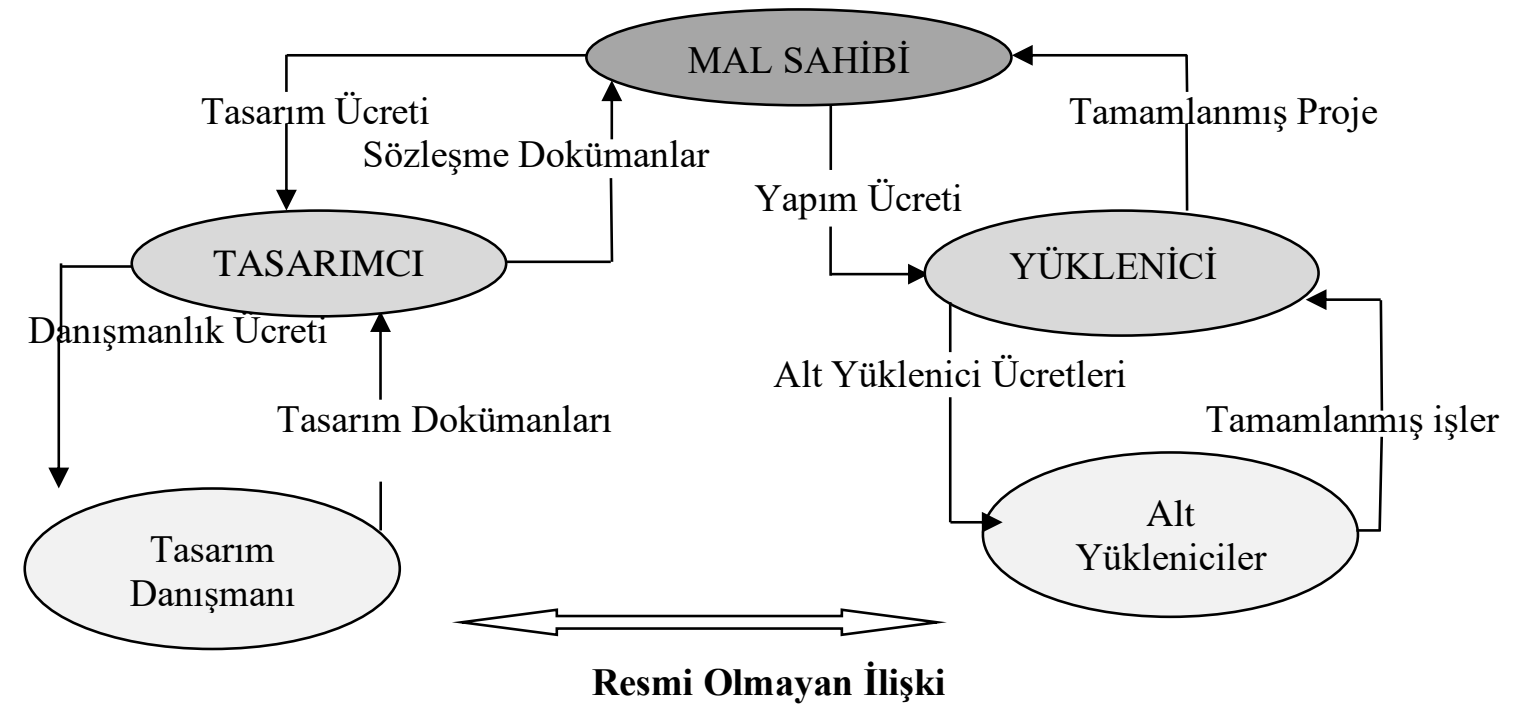

Şekil 1: Geleneksel PTS`de Katılımcı İlişkileri (Gould, 2000; Erbaş, 2013).

Geleneksel PTS`de mal sahibi öncelikle tasarım hizmeti için tasarımcı ile sözleşme yapar. Tüm tasarım dokümanları (mimari proje, statik projesi, tesisat projeleri vb) tamamlandıktan sonra mal sahibi tasarımcının danışmanlığında yükleniciyi seçer. Tasarım tamamlanmadan yapım aşamasına başlanılamaz. Yüklenici seçiminde temel kriter "ekonomik açıdan en avantajlı isteklinin" seçilmesidir. $\mathrm{Bu}$ nedenle ihale en düşük fiyat teklifini veren istekliye bırakılır. İhaleyi kazanan yüklenici de yapım ücreti karşıllı̆ında yapım işini gerçekleştirme sorumluluğunu üstlenir. Bu süreçte tasarımcı ve yüklenici arasında herhangi bir sözleşme ilişkisi kurulmaz ve yüklenici tasarım aşamasında yer almaz.

KIKK, hızlı proje üretimi ve inşası konusunda iyileştirmeye ihtiyaç duyulan bir yapıya sahiptir. KIK 'in geleneksel PTS nin dezavantajlarından kaynaklanan olumsuz yapısı COVID-19 pandemisi ile mücadele sürecinde pandemi hastanesi olarak hizmet verecek yeni geçici ve kalıc1 sağl1k yapılarının;

- Minimum sürede,

- Minimum maliyetle

- Maksimum kalitede

inşa edilmesinde hedeflenen başarının sağlanması açısından önemli bir engel teşkil etmektedir. Bu nedenle KİK mevzuatında kalıcı değişiklikler yapmak ve hızla uygulamaya geçirmek oldukça önemlidir.

Süre açısından incelendiğinde tasarım, ihale ve yapım sıra düzeni içinde gerçekleştirilen kamuya ait yapım işlerinin tamamlanmasının yapım aşamasına tasarım tamamlanmadan başlanılamadığı için daha uzun sürede gerçekleştiği görülmektedir.

Maliyet açısından incelendiğinde mevcut sistemde her ne kadar ihale öncesi tüm projelerin tamamlanmış olmasına rağmen yapım öncesinde işin maliyetiyle ilgili kesin bilgiye sahip olunsa da, yapım sırasında gerçekleşen değişikliklerin sözleşme ve diğer dokümanlara yansıtılmasında yaşanan zorluklar maliyet artışına neden olan problem alanını oluşturmaktadır.

Kalite açısından incelendiğinde ise mevcut sistemde ihalenin ekonomik açıdan en avantajlı teklif sahibine verilmesinin temel şart koşulması nedeniyle ihaleyi alabilmek için ihale aşamasında 
en düşük fiyat teklifini verme isteğindeki yüklenicinin, yapım aşamasında fiyat kaygısı nedeniyle işin kalitesinden ödün verdiği görülmektedir. Bu durum kamu yapılarının yapım kalitesinin düşmesine neden olmaktadır.

Tüm bu faktörler değerlendirildiğinde COVID-19`la mücadele sürecinde yapılan yatırımlarda önemli bir paya sahip olacak olan geçici veya kalıcı sağlık birimlerinin temini sürecinde süre, maliyet ve kalite açısından avantaj sağlayacak yeni düzenlemelerin yapılmasının gerekliliği oldukça açıktır.

\section{Yapım Yönetimi Proje Teslim Sistemi}

Yapım yönetimi sistemi yapım projelerinde kullanılan üç temel proje teslim sisteminden biridir. Construction Specifications Institute (CSI) (2005) yapım yönetimi kavramını bir projenin ilk aşamasından son aşamasına kadar süresini, maliyetini ve kapsamını kontrol etmek için uygulanan profesyonel yönetim süreci olarak tanımlamaktadır. Buna göre yapım yöneticisi, mal sahibi tarafından mal sahibinin projedeki görevlerini onun adına yerine getirmek amacıyla görevlendirilen kişi ya da kurumdur.

Yapım yönetimi sistemi yapım endüstrisinin artan karmaşıklığına yanıt olarak ortaya çıkmıştır. Profesyonel yapım yönetimi hizmetlerinin uygulanması gerek kamu ve gerekse özel sektörde planlama, tasarım ve yapım süreçlerinin etkin bir şekilde denetlenmesi, yapım projelerinin başarılı bir şekilde tamamlanması açısından verimli bir araç olarak tanımlanmıştır (CMAA, 2002).

Construction Management Association of America- (CMAA) (2002) yapım yönetimini mal sahibi için büyük ölçekli projelerde başarılı bir şekilde uygulanması amacıyla oluşturulmuş bir yönetim sistemi olarak tanımlamaktadır. Bu sistemde yapım yöneticisi kalite, maliyet, zaman ve saha yönetimini içeren proje amaçlarının başarılması için planlama, tasarım, yapım ve yapım sonrası aşamaları programlamaktadır. Halpin ve Woodhead (1998) ise yapım yönetimini ön tasarım, tasarım ve yapım aşamalarında yürütülen, yapım sürecinde süre ve maliyet kontrolü sağlayan bir yönetim faaliyeti olarak tanımlamaktadır.

British Columbia Construction Association (BCCA) (2000), yapım yönetiminin belirli bir sözleşme bedeli karşılığı, MS nin çıkarları doğrultusunda saha yönetimi, danışmanlık, yönetim ve teknik servis hizmetlerini sağlamak için tek bir kişi ile sözleşme yaptığı bir proje teslim sistemi olduğunu vurgulamaktadır.

Flake ve Olliff (2001) yapım yönetiminin bir yapım projesinin çeşitli aşamalarına, uzman üçüncü katılımcının yapım liderliği sağladığı bir süreç olduğunu ifade etmektedir. Sürecin en önemli özelliği bu katılımcının varlığı ile tasarım ve yapım aşamalarının birlikte yürütülmesidir. Sistem projenin maksimum kalitede ve en düşük maliyetle, en kısa sürede teslim edilmesini hedefleyen bir takım yaklaşımına sahiptir (Şekil 2). 


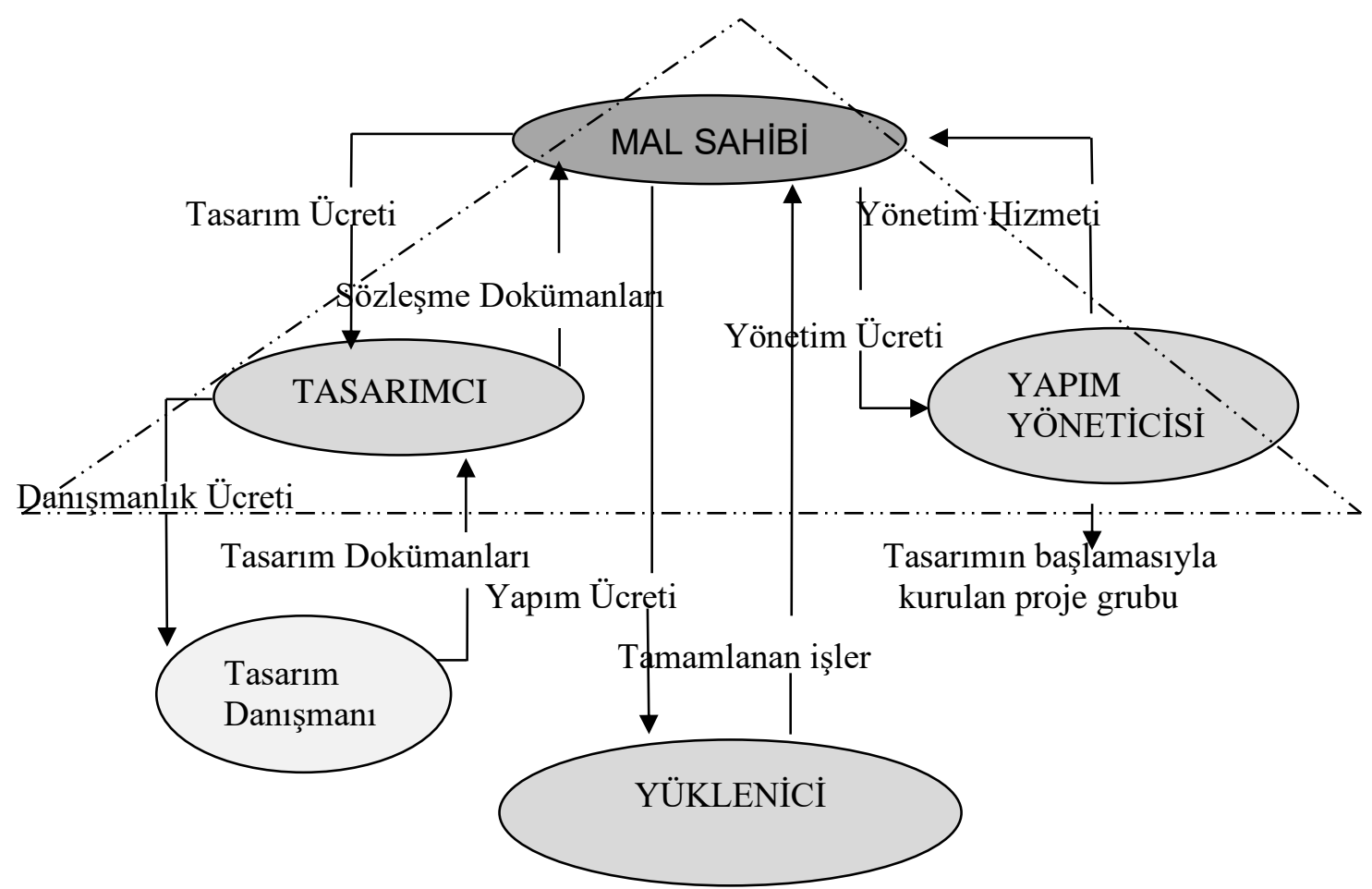

Şekil 2: Yapım Yönetimi PTS`de Katılımcılar Arasındaki İlişkiler (Gould, 2000; Erbaş, 2013).

Sözleşme ilişkileri açısından değerlendirildiğinde yapım yönetimi PTS`de mal sahibi tasarımcıya ödeyeceği tasarım ücreti karşılığında yapıya ilişkin tüm projeleri temin eder. Bu ilişkide tasarımcı sözleşme dökümanlarını da hazırlamakla sorumludur. Yüklenici ile kurulan sözleşme ilişkisinde yüklenici sözleşme dökümanlarına uygun olarak yapım işini üstlenir. Yapım yöneticisinin bu sistemdeki rolü gerek tasarım gerekse yapım aşamasında mal sahibinin temsilcisi ve danışmanı olmaktır. Yapım konusundaki bilgi ve deneyimiyle tasarım aşamasına dahil olur ve her ne kadar tasarım sorumluluğu bulunmasa da mal sahibinin bu aşamadaki danışmanı olarak tasarımın yapıma ilişkin eksik yönlerinin geliştirilmesine katkı sağlar. Benzer bir şekilde yapım aşamasında yine mal sahibinin sahadaki temsilcisi olarak hareket eder ve yapıma ilişkin aksaklıkların giderilmesini sağlar. Geleneksel PTS'den farklı olarak tasarım aşamasında yapım deneyimine sahip bir proje katılımcısının yer alması olası aksaklıkların erken safhalarda giderilmesini sağlar. Diğer taraftan yapım yöneticisi her iki aşamada yapacağı maliyet hesapları ile yapım sürecinde maliyet kontrolünün sağlanmasına imkan verir. Bu sistemde yapım yöneticisinin mal sahibi dışındaki diğer aktörlerle herhangi bir sözleşme ilişkisi söz konusu değildir. Sistem aynı zamanda geleneksel PTS ’nin aksine yapım ve tasarım aşamalarının eş zamanlı yürütülmesine imkan verir.

$\mathrm{Bu}$ uygulamada, tasarım sürecinde yapım işi konusunda deneyimli bir katılımcının yer alması tasarımda oluşabilecek hataların engellenmesini sağlamıştır. Projenin süre, maliyet ve kalite hedeflerinin en verimli şekilde başarılmasına yardımcı olmuştur. Böylelikle yapım yönetimi sistemi özellikle ABD`de büyük ölçekli ve kapsamlı projelerde birçok kamu ihalesinde tercih edilir bir PTS haline gelmiştir (Erbaş, 2013).

\section{Yapım Yönetimi Proje Teslim Sisteminin Kamu İdarelerine Sağlayacağı Avantajlar}

Yapım yönetimi PTS`nin kullanımı son yıllarda oldukça yaygınlaşmıştır. Sistemin sağladığı avantajlar yalnızca özel sektör ile sınırlı değilidir. Aynı zamanda kamu kurumları açısından da aynı 
avantajlar söz konusudur. $\mathrm{Bu}$ yöntem mal sahibine yapım işlerini kendi organizasyonu içinde adına yönetecek firmayı görevlendirme imkanı vermektedir. İş akış süreçleri açısından karşılaştırıldığında geleneksel PTS ve yapım yönetimi PTS arasında önemli farklılıklar bulunmaktadır (Şekil 3). Bu iki sistem arasındaki farklılıklar yapım yönetimi PTS`nin de süre, maliyet ve kaliteye etki eden temel avantajlarını ortaya koymaktadır.

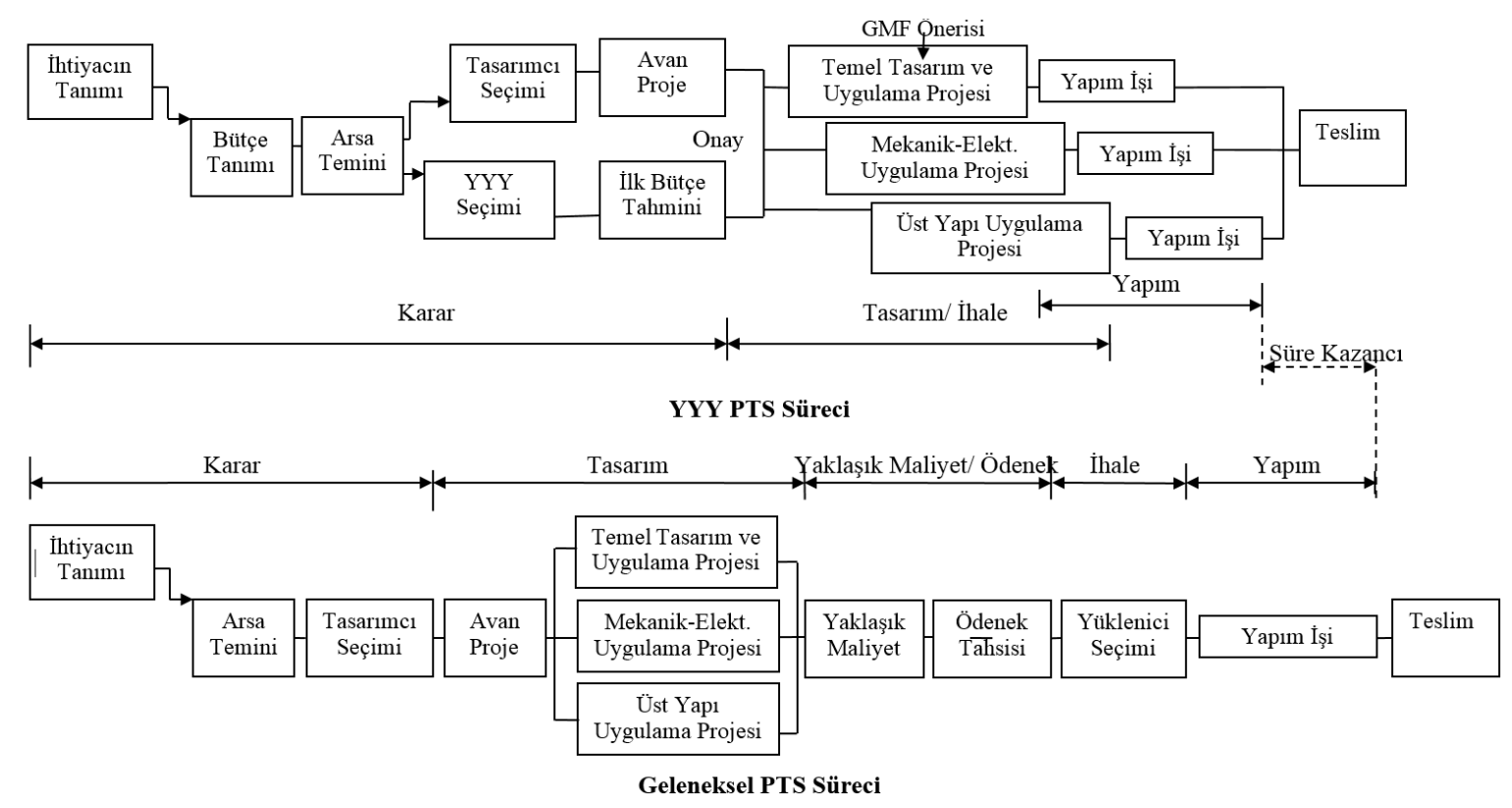

Şekil 3: Geleneksel PTS ve Yapım Yönetimi PTS İş Akış Süreçleri (Erbaş, 2013)

Yapım yönetimi proje teslim sistemin temel avantajları şunlardır:

1. Katılımcılar arasında iyi ilişkilerin kurulması: Her iki sistemin katılımcılar arasındaki ilişki şeması karşılaştırıldığında yapım yönetimi PTS`de tasarım ve yapım aşamasında mal sahibi, tasarımcı ve yüklenici arasında iyi bir ilişki kurulduğu görülmektedir. Bu ilişki projenin tamamlanmasına kadar devam eder. $\mathrm{Bu}$ da yapım yöneticisinin tasarım firmasını önceden denetleyebilmesine ve ihale dosyasının hazırlanmasına olanak sağlamaktadır. Yapım yönetimi PTS de iyi bir düzenlemenin sağlanması için mal sahibi, tasarımcı ve yapım yöneticisi arasında iyi bir ilişki ve birliktelik kurulmalıdır. Katılımcılardan birinin uyumsuz, iletişimsiz hale gelmesi sistemin sağlamış olduğu tüm avantajları ortadan kaldırmaktadır. $\mathrm{Bu}$ sistem paylaşmaya ve katılımcıların birbirlerine olan güvenlerine dayanmaktadır ve bu gereklilikler proje süresince test edilmektedir. Mal sahibinin projeye dahil olması ve yapım hakkında bilgi sahibi olması bu sistemde oldukça önemlidir. Prensip olarak mal sahibi, tasarımcı ve yapım yöneticisinden oluşan proje takımında yer alan her katılımcının üstlendiği rol ve sorumluluklar da geleneksel sistemdeki sorumluluklardan farklıdır. Yapım yönetimi proje teslim sisteminde yapım yöneticisi tasarımcı ve yüklenici seçiminde söz sahibidir. Amaç mal sahibine en iyi hizmetin verilmesi ve en iyi ürünün ortaya çıkarılması olduğu için oluşacak problemlerin çözümü iki tarafın da katkılarıyla sağlanmaktadır.

2. Aşamalı yapıma izin verme: Yapım yöneticisi projeye erken safhalarda dahil olduğu için sistem aşamalı yapıma izin verebilmektedir (Şekil 4). Geleneksel sistemde tasarım, ihale ve yapım aşamaları ardarda ilerlemek zorundadır. Tasarım tamamlanmadan yapım aşamasına geçilemez. Ancak yapım yönetimi sisteminde yapım işi farklı alt iş paketlerine bölünüp bu iş paketleri birbirlerine paralel olarak yürütülebilir. Dolayısıyla yapım işinin başlaması için tasarım 
aşamasının tamamen tamamlanmış olma şartı aranmaz. Bu da süre açısından mal sahibine önemli avantajlar sağlar.

Geleneksel yapım işi sıra düzeni

\begin{tabular}{|c|c|c|}
\hline Tasarım & Temin & Yapım \\
\hline
\end{tabular}

Tamamlanma

1.Paket

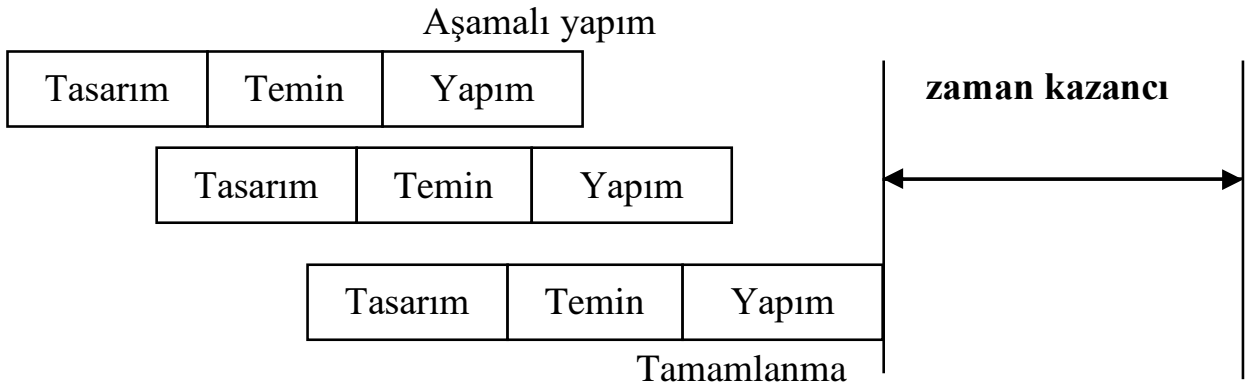

Şekil 4: Aşamalı yapım şeması (Gould, 2000)

3. Farklı uzmanlık alanları için ayrı sözleşmeler yapılması: Mal sahibi tek bir genel yüklenici yerine her bir iş paketi için farklı alt yüklenicilerle sözleşme yapabilir. Farklı alt yükleniciler yapım aşamasında yapım yöneticisi tarafından kontrol edilir. Böylelikle iş paketlerinin birbiriyle koordinasyonu sağlanır. Mal sahibi yaptığı alt yüklenicilik sözleşmeleriyle rekabet ortamı oluşturup maliyet tasarrufu sağlayabilir. Ancak geleneksel sistemde mal sahibi tek bir genel yüklenici ile sözleşme yapar. Bu nedenle alt yüklenicilerin rekabet ilişkisinden maliyet karı sağlayamaz.

4. Sözleşme değiştirilmeden değişikliklere izin verme: Yapım aşaması sırasında değişiklikleri yürütmek geleneksel PTS`deki kadar zor değildir. Geleneksel PTS`de yapım aşamasında yapılan değişiklikler tasarım tamamen tamamlandığı ve yapım bedeli yapım öncesi kesinleştiği için mal sahibi ve yüklenici arasındaki yapım sözleşmesinde değişikliğe neden olur. $\mathrm{Bu}$ durum çoğu zaman taraflar arasında anlaşmazlıkla sonuçlanır. Yapım yönetimi sisteminde aşamalı yapımın uygulanmasıyla tasarım ve yapım işlerinin paralel ilerlemesi nedeniyle sözleşmede herhangi bir değişiklik yapılmadan proje üzerinde değişiklik yapılabilir. Çoğu zaman söz konusu değişiklikler resmi olmayan bir şekilde de gerçekleşebilmektedir.

5. Yapım uzmanının tasarıma dahil olabilmesi: Geleneksel PTS 'den farklı olarak tasarım aşamasında yapım yöneticisi yapım deneyimini de kullanarak tasarım kararlarında mal sahibi adına danışman rolü üstlenmektedir. Bu avantaj yapım aşamasında tasarımdan kaynaklanan hata oranının da azalmasına imkan tanır.

6. Maliyet kontrolüne izin verme: Yapım yöneticisi tasarım aşamasında ve yapım aşamasında MS`ne maliyet kontrolü hizmeti sağlar. Böylelikle mal sahibi alınan tasarım kararlarının, malzeme tercihlerinin maliyete nasıl etki ettiğini görme imkanına sahip olur. Her ne kadar geleneksel PTS `de olduğu gibi yapım aşamasına başlamadan önce kesin maliyet bilgisi sağlanamasa da mal sahibi işin yaklaşık maliyeti hakkında bilgi sahibi olur (Collier,1994; Ritz, 1994; Gould, 2000; Peck, 2001).

\section{Değerlendirme}

Dünyada Covid-19 pandemisinin ortaya çıkmasıyla önce insani boyutta ve ardından ekonomik boyutta karşılaşılan sonuçların şimdiye kadar hiçbir krizde karşılaşılmadığı kadar büyük zararlara yol açtığı gözlemlenmektedir (Oran, 2020). Çalışmak kapsamında ele alınan avantajlar 
genel olarak değerlendirildiğinde yeni bir proje gerçekleştirme metodu olarak Avrupa da, özellikle ABD`de uzun yıllardır kullanılmakta olan yapım yönetimi sisteminin COVID-19 pandemi sürecinde sağlık yapılarının temininde uygulanması kamu idarelerine önemli avantajlar sağlayacak ve sözkonusu zararların azaltılmasına imkan tanıyacaktır. Çünkü yapım yönetim sistemi hem tasarım hem de yapım deneyimine sahip bir proje aktörü olan yapım yöneticisinin de yapım sürecine katılımını sağlayan ve kamu kurumlarına süre, kalite ve maliyet avantajı sağlayan çok yönlü bir proje teslim sistemidir.

Yapım yöneticisinin yeni bir proje katılımcısı olarak sürece dahil olması kamu idarelerine sağlanan en önemli avantajlardan birini oluşturmaktadır. Yapım yöneticisinin tasarım ve yapım konusunda herhangi bir sorumluluğa sahip olmaması, süreci yalnızca kamu idaresi adına denetleyecek olması COVID-19 pandemi sürecinde karşılaşılabilecek çeşitli sorunların da azaltılmasına ve projenin kalite hedeflerinin başarılmasına imkan tanıyacaktır.

Diğer taraftan pandemiyle mücadele sürecinde sağlık yapılarının hızla inşa edilmesi oldukça önemlidir. Yapım yönetimi proje teslim sisteminin aşamalı yapıma izin vermesi, sözleşme değiştirilmeden değişikliklere imkan tanıması, farklı uzmanlık alanları için farklı sözleşmeler yapılabilmesi gibi temel avantajları bu süreçte sağlık yapılarının daha kısa sürede inşa edilmesine de katk1 sağlayacaktır. Yapıların kısa sürede tamamlanarak hizmete girmesiyle ihtiyaç duyulan yatak kapasitesinin de karşılanması mümkündür. Pandemi süreci gerekli tedbirler alınmadığı durumda farklı seyirler gösterebilir. Hastalığın artış gösterdiği süreçlerde sağlık hizmetine duyulacak ihtiyaç da paralel olarak artacaktır. Bu nedenle olası artışlara karşı mutlaka yapı kapasitesi açısından hazırlıklı olunmalidır.

Tüm bunlara paralel olarak maliyet kontrolüne izin veren bu sistemin uygulanmasıyla kamu idarelerinin sağlık yapılarının yapımı sırasında geleneksel sistemden farklı olarak maliyet avantajı sağlayacakları da oldukça açıktır. Kamu idareleri yürüttüğü her türlü faaliyette kamu kaynaklarını kullanmaktadır. Bu nedenle sağlık yapılarının temininde sistemin maliyet avantajı sağlaması kamu kaynaklarının da verimli kullanılmasını sağlar.

Özel sektör ihale uygulamalarında çoğu zaman KİK’den de faydalanmaktadır. KİK’e yapım yönetimi PTS nin uyarlanması, bu sistemin özel sektör temsilcileri tarafindan da benimsenmesine imkan tanıyacaktır. ABD`de çok uzun bir zamandır uygulanıyor olmasına rağmen sistemin Türkiye de henüz uygulama alanının bulunmaması gerek kamu sektörü gerekse özel sektör açısından oldukça olumsuz bir durum teşkil etmektedir. COVID-19 pandemi süreciyle birlikte yapım yönetimi PTS nin başta kamu kurumlarında olmak üzere tüm alanlarda uygulama alanı bulabilmesi yapım sektörünün de gelişmesini sağlayacaktır.

\section{Sonuç}

COVID-19 pandemisi ile mücadele sürecinde KİK`e tabi olan sağlık yapılarının inşa faaliyetlerinin hızlı bir şekilde tamamlanması önemlidir. Aksi takdirde ortaya çıkan sağlık talebi karşılanamayacaktır. Bu durum çoğu Avrupa ülkesinde görüldüğü gibi sağlık sisteminin çökmesine neden olacaktır. Ancak KİK mevzuatı proje maliyet, kalite ve süresine etki eden sorunlu bir yapıya sahiptir. Bu noktada bu çalışma COVID-19 mücadele sürecinde sağlık yapılarının hızlı bir şekilde inşa edilmesi için KİK mevzuatına fayda sağlayacak yeni bir proje teslim sistemi modeli olarak yapım yönetimi PTS`nin kamu idarelerine sağlayacağı temel avantajları ortaya koyma görevini üstlenmektedir.

Kamu kaynaklarının devlet tarafından etkin ve verimli kullanılması toplumsal güvenin ve refahın oluşturulmasında önemli bir etkiye sahiptir. Bu nedenle COVID-19 pandemi sürecinde sağlık yapılarının inşai faaliyetlerinin gerçekleştirilmesi konusunda gösterilmesi gereken hassasiyet bir kez daha önem kazanmaktadır. COVID-19 karşısında artan sağlık hizmeti talebinin karşılanması amacıyla kamuya ait yeni sağlık yapılarının da hızlı bir şekilde inşa edilmesi gerekliliği ortaya 
çıkmaktadır. Sağlık yapılarının sahip olduğu karmaşık fonksiyonlar ve ihtiyaç duyulan modern malzeme ve yapım tekniği kullanımı konularındaki gerekli uzmanlık bilgisi, bu yapıların inşai faaliyetinin yürütülmesinde özel uygulamaların geliştirilmesini gerektirmektedir.

Yapım yönetimi PTS`nin COVID-19 pandemisiyle mücadele sürecinde sağlık yapılarının temininde alternatif bir PTS olarak uygulanması kamu idarelerine önemli avantajlar sağlayacaktır. KIKK’e uygun olarak yürütülen geleneksel PTS ile karşılaştırıldığında yapım yönetimi PTS nin kamu idarelerine;

- daha kisa süre,

- daha yüksek kalite ve

- daha düşük maliyet

sağlaması açısından önemli avantajlara sahip olduğu tespit edilmiştir. Kalite, süre ve maliyete etki eden avantajlar temel olarak sürece geleneksel PTS'de yer almayan yapım yöneticisinin dahil olmasından ve sözleşme ilişkilerinden kaynaklanmaktadır. Yapım yöneticisi gerek tasarım gerekse yapım konusundaki deneyimi ile tarafsız bir katılımcı olarak yapım sürecinin daha başarılı bir şekilde yürütülmesine katkı sağlayacak bir aktördür. Sistemin KİK’e uyarlanmasının özel sektör tarafından da yapım yönetimi sisteminin benimsenmesine imkan tanıyacağı ve böylelikle yapım sektörünün gelişimine katkı sağlanacağı düşünülmektedir.

Sonuç olarak yapım yönetimi PTS sahip olduğu avantajları ile pandemi döneminde Türkiye' de sağlık yapıların hızlı bir şekilde temin edilmesi hususunda mevcut sistemdeki aksaklıkları gidermeye yönelik yeni bir proje teslim sistemi olma özelliğine sahiptir. Bu nedenle gelecek çalışmalarda yapım yönetimi sisteminin KİK mevzuatına uyarlanması hususunun ele alınması önerilmektedir.

\section{Kaynakça}

Akçay, C., \& Manisalı, E. (2007). 4734 Sayılı Kamu İhale Kanunu ve 4735 Sayılı Kamu İhale Sözleşmeleri Kanununun, AB Uygulamaları Çerçevesinde Uygulamada Karşılaşılan Sorunlar Açısından İncelenmesi.

Akgül, A. (2006). Devlet İhale Kanunu'ndan Kamu İhale Kanunu'na. Danıştay Dergisi, 111.

Bingül Ak, B., Türk, A., Ak, R. (2020). Covıd-19 Bağlamında Tarihteki Büyük Salgınlar ve $\begin{array}{lllll}\text { Ekonomik Sonuçları. Turkish } & \text { Studies, } & 15(4), & \text { 189-200. }\end{array}$ https://dx.doi.org/10.7827/TurkishStudies.44242

British Columbia Construction Association (BCCA), (2000). Recommended Guidelines For the Use of Construction Management as a Project Delivery Method. BCCA Documents.

Collier, K. (1994). Managing construction: the contractual viewpoint. Delmar Pub.

Coşgun, T. (2009). Kamu İhale Yasası Ve Uygulamada Karşılaşılan Sorunlar Üzerine Bir İnceleme. TMMOB İnşaat Mühendisleri Odası.

Çıragil, P. (2020). Ne İlkti Ne de Son Olacak. National Geographic, 228, 34-35.

Erbaş, İ. (2013). Türkiye 'deki Kamu Ihalelerinde Bir Proje Gerçekleştirme Biçimi Olarak Yapım Yönetimi Modeli (Yayınlanmamış Doktora Tezi). İstanbul: İstanbul Teknik Üniversitesi Fen Bilimleri Enstitüsü.

Flake, R. P. ve Olliff, D. (2001). Construction Manager At Risk, What's in A Name? 14th Annual Construction and Law Conference. 
Gould, F. E. (2000). Construction Project Management, Wentworth Institute of Technology, Vary E. Joyce, Massachusetts Institute of Technology.

Halpin, D. W. ve Woodhead, R. W. (1998). Construction Management. Wiley.

Kortunay, A. ve Sezer, Y. (2007). Kamu İhale Kanununun 63. Maddesinin AB Hukuku Perspektifinden Değerlendirilmesi. Ankara Üniversitesi Hukuk Fakültesi Dergisi, 56 (3), 137-171.

Oran, İ. B. (2020). Covid-19'un uluslararası turizm üzerinde diğer krizlerden farklı etkileri. Turkish Studies, 15(4), 807-826. https://dx.doi.org/10.7827/TurkishStudies.44282

Peck, B. V. (2001). Construction Management: Choosing the Best Project Delivery Method. Facilities Manager, 17(2), 31-38.

Ritz, G. J. (1994). Total construction project management. McGraw-Hill

The Construction Management Association of America (CMAA). (2002). An Owner's Guide To Construction: Management Assuring Project Success Under Any Delivery Method. CMMA.

The Construction Specifications Institute (CSI). (2005). The Project Resource Manual CSI Manual of Practice (Fifth Edition). McGraw-Hill.

Url-1, <https://www.trthaber.com/haber/saglik/ulke-ulke-yogun-bakim-yatak-kapasitesi469647.html> Son Erişim Tarihi:23.06.2020

Url-2, < https://www.msn.com/tr-tr/haber/dunya/\%C3\%A7indeki-koronavir\%C3\%BCs-hastanelerikapat\%C4\%B11\%C4\%B1yor/ar-BB10YMvh> Son Erişim Tarihi:23.06.2020

Yenal, S. (2020). COVID-19 salgınının uluslararası güvenlik açısından değerlendirilmesi. Turkish Studies, 15(4), 1315-1329. https://dx.doi.org/10.7827/TurkishStudies.43645

World Health Organization (WHO), (2020a). Operational Considerations for Case Management of COVID-19 in Health Facility and Community Interim Guidance.

World Health Organization (WHO), (2020b). Health Systems Respond to COVID-19 Technical Guidance \#2 Creating surge capacity for acute and intensive care Recommendations for the WHO European Region. 